\title{
The design of a small-scale multi-stage desalination plant driven by the exhaust of diesel generators
}

\author{
R. Jammoul ${ }^{1} \&$ O. A. El-Samni ${ }^{2}$ \\ ${ }^{1}$ Mechanical Engineering Department, Beirut Arab University, Lebanon \\ ${ }^{2}$ Faculty of Engineering, Mechanical Engineering Department, \\ Alexandria University, Egypt
}

\begin{abstract}
The present study provides an energy-saving design of a desalination plant that uses the waste heat of the exhaust of a diesel generator. The proposed model consists of a multistage flash (MSF) desalination unit in which the sea water is heated by the flue gases instead of steam. A mathematical model is derived to design the entire plant including the waste heat recovery heat exchanger and the MSF plant. The model is flexibly designed in order to deal with wide range of diesel generators rates and any number of stages of MSF. A database of diesel generator sets are imported including temperature of exhaust, gas flow rates and the back pressures for each set. Two test cases are carried out with two different salinity levels and diesel generator rates, results show that the amount of distilled water in $\mathrm{kg} / \mathrm{s}$ can be correlated to the rate of diesel generator according to the second order polynomial: $0.54+4.1 \times 10^{-3}(\mathrm{kVA})+4.1 \times 10^{-6}(\mathrm{kVA})^{2}$ in the case of brackish water and $0.36+2.7 \times 10^{-3}(\mathrm{kVA})+3.1 \times 10^{-6}(\mathrm{kVA})^{2}$ in the case of seawater. The survey of power generation in Lebanon reveals that the waste heat from a diesel generator can be utilized to get around 100 million $\mathrm{m}^{3}$ of distillate water usable for drinking and for domestic use. This quantity can provide fresh water for more than 300,000 person/year. The performance of proposed plant is assessed during summer and winter conditions and the model can deal with any salinity ranges.
\end{abstract}

Keywords: desalination, waste heat, diesel generators, MSF. 


\section{Introduction}

The Arab countries are generally regarded among those extremely needy for fresh water natural resources. The Arab countries represent only 5\% of the earth's population, as the population in the Arab world reached 260 million in 1995. Regarding its area, the Arab World takes up to $10 \%$ of the earth's area, and yet its fresh water resources do not exceed $0.5 \%$, Figure 1 illustrates the fresh water resources and the individual share of fresh water in the Arab countries. A decrease in the share of the Arab citizen is noticeable, reaching far below the water poverty index $\left(1500 \mathrm{~m}^{3}\right)$ assigned by World Health Organization [1]. The situation is worsening within the upcoming years, with the increase of population and development.

Moreover, it is rare to find natural resources for fresh water in countries like the Persian Gulf countries and North African countries, This, therefore, imposes cooperation and coordination among the Arab countries and their neighbours [2]. Water supplies in these countries cannot meet urban and industrial development needs as well as associated changes in lifestyle. Moreover, common use of poor water in developing countries causes $80-90 \%$ of all diseases and $30 \%$ of all deaths. Continued water scarcities will affect the region's social and economic potential, increase land vulnerability to salinization and desertification and raise the risk for political conflict around the limited water available [3]. Even in the industrial countries, long dry seasons and limited rainfall force governments, states, and municipalities to adopt severe water restriction programs that affect the population at large [4], the main solution for these countries is the sea water desalination techniques which is the most important for achieving the people water needs. The desalination processes can be split into two major categories: thermal and membrane processes.

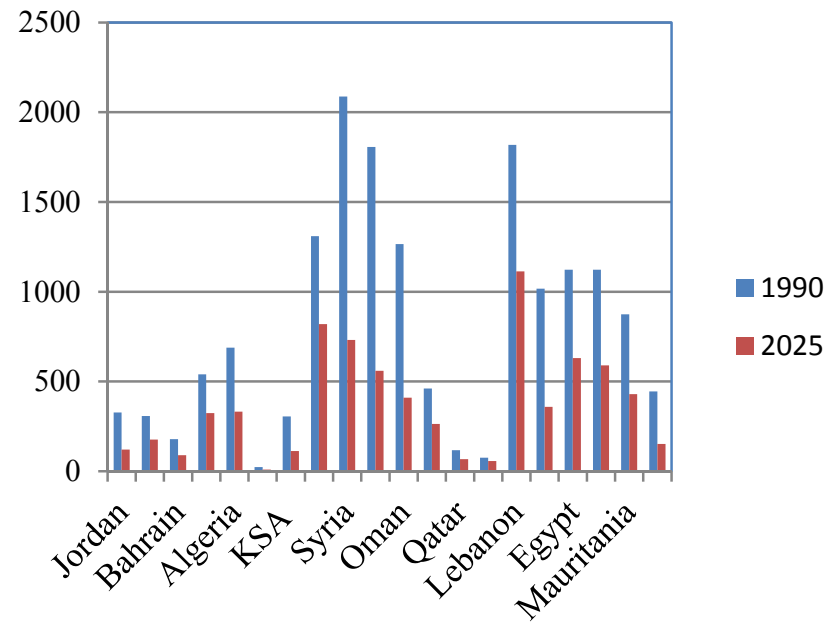

Figure 1: Traditional water resources in Arab countries. 
The greatest advantages of thermal desalination processes is being driven by any type of thermal sources such as the waste heat and solar energy collectors and has less electricity consumption. The thermal desalination processes includes: multi-stage flash distillation (MSF), multi-effect distillation (MED), thermal vapor compression (TVC), mechanical vapor compression processes (MVC). Membrane processes including reverse osmosis (RO) [5]. Development of more productive models of MSF is essential in the Arab region suffering from water scarcity.

On the other hand in industrial and power generation there is a portion of the energy input which is discarded as waste heat [6]. The efficiency of such systems is directly proportional to the heat that can be recovered. For example, the internal combustion engine has efficiency not more than $40 \%$ of the input energy. The remaining energy is being lost in the cooling water, exhaust system, and as radiation. Much of this waste heat is recoverable by relatively simple means. There are many different heat recovery methods available for capturing engine waste heat, including thermal electric conversion; heat-to-power conversion direct heat application heat for refrigeration and air conditioning; and heat for desalination which will be used in present study.

The objective of this study is to design a small scale MSF desalination plant that can be driven by the waste heat of Diesel engines. A simple program is designed in order to provide the expected distilled water based on the rate of diesel generator sets available and the space which can accommodate the MSF plant. The study will provide details of the heat exchanger used to heat the brine, number of the MSF chambers, their specifications that fit with the available space, and an estimation of the payback time for the proposed unit. The performance of the proposed unit in summer and winter can be assessed and the degree of the water salinity is considered as well.

\section{Motivation}

A survey of the diesel generator sets in Lebanon has been carried out which reveals the availability of various rates ranging between $100 \mathrm{~kW}$ to $2 \mathrm{MW}$ sets. The total production of diesel generators contributed $34 \%$ of the total electricity production in 2009. In numbers, diesel generators produced $4434 \mathrm{GWh}$ and the EDL produced $8056 \mathrm{GWh}$ while the remaining is $701 \mathrm{GWh}$ as suppressed demand [7]. Assuming that the feasible recovered amount of waste heat to be $80 \%$ of total waste heat, therefore the available energy for desalination or any other heat processes can be around $2000 \mathrm{GWh}$. Multi-flash stage desalination needs $22.13 \mathrm{kWh} / \mathrm{m}^{3}$ distilled water [8]. Therefore, the expected distillate water production using the $2000 \mathrm{GWh}$ as the waste energy from different types of diesel engines is estimated to be 100 million $\mathrm{m}^{3} /$ year. Based on the statistics of individual consumption of water in Lebanon [9], this amount may be sufficient to provide fresh water to around 400,000 person/year. Databases of the exhaust gases temperature, flow rate, allowed back pressure are accumulated for different sizes of diesel generators in the Lebanese market as listed in . 


\section{Literature review}

Utilizing the waste heat in seawater desalination has not attracted the expected interests of researches. However, couple of projects could be surveyed in 1960s. The pioneer research in using diesel waste in desalination was by the Navy. It relies almost entirely on diesel electric generator plants at all its bases. In 1968, Williams and Hodgson [10] used 25 MSF plant constructed from aluminium to reduce the weight and could produce around 9-22 $\mathrm{m}^{3} / \mathrm{d}$ for diesel engines of 60 and $150 \mathrm{~kW}$ capacities, respectively. The Ebeye (Marshall Islands) sea water desalination project used the waste of diesel station of 3.2 MW capacity and produced $1100 \mathrm{~m}^{3} / \mathrm{d}$ using 12 effects of MED [11]. Rautenbach and Arzt [12] discussed several alternatives of thermal energy supply for evaporation processes including MSF and carried out cost analysis to utilize the waste heat of $10 \mathrm{MW}$ gas turbine. They estimated the distilled water to be $4000 \mathrm{~m}^{3} / \mathrm{d}$. Another study on using the waste of gas turbine for seawater desalination was carried by Aly [13].

His thermal analysis revealed that a gas turbine of $32 \mathrm{MW}$ can produce around $11750 \mathrm{~m}^{3} / \mathrm{d}$. Moustafa et al. [14] introduced the concept of a total energy, diesel powered greenhouse-desalination system that offers a reasonable approach to agricultural production in remote arid areas. The electric generator is driven by a diesel engine to provide the electric energy requirements for the integrated complex. The heat rejected by the engine cooling system is recovered by a heat pipe that provides the thermal energy needed by a MSF desalination unit. The fresh water production $M_{d}$ in $\mathrm{kg} / \mathrm{hr}$ was estimated as a function of the electric energy output of the diesel generator expressed by $\mathrm{M}_{\mathrm{d}}=0.29 .2+13.4 \mathrm{~kW}_{\mathrm{e}}$.

\section{Proposed model}

The main idea of the present project is to prepare a robust mathematical model that can deal with different diesel capacities. More than 25 model of diesel generators could be collected from companies in Lebanon. A sample of them are listed in . The model integrates the full them with a MSF plant with varying number

Table 1: Technical data for various Diesel engines power.

\begin{tabular}{|l|c|c|c|c|c|}
\hline Model & Engine & $\begin{array}{l}\text { Engine } \\
\text { power }(\mathrm{kW})\end{array}$ & $\begin{array}{c}\text { Exhaust } \\
\text { gas flow } \\
\left(\mathrm{m}^{3} / \mathrm{min}\right)\end{array}$ & $\begin{array}{c}\text { Exhaust } \\
\text { gas temp. } \\
\left({ }^{\circ} \mathrm{C}\right)\end{array}$ & $\begin{array}{c}\text { Back } \\
\text { pressure } \\
\left(\mathrm{mm} \mathrm{H}_{2} \mathrm{O}\right)\end{array}$ \\
\hline PT 9 & 403D-11G & 7.2 & 1.8 & 420 & 1040 \\
\hline PT 20 & 404D-22G & 18.4 & 3.64 & 445 & 1040 \\
\hline PT 60 & 1103A-33TG2 & 53.8 & 10.1 & 557 & 1092 \\
\hline PT 100 & 1104C-44TAG2 & 99.5 & 15.2 & 514 & 1835 \\
\hline PT 200 & 1306C-E87TAG3 & 180 & 36.5 & 524 & 1070 \\
\hline PT 400 & 2206A-E13TAG3 & 368 & 64.6 & 630 & 1000 \\
\hline PT 800 & 4006A-23TAG3A & 705 & 193 & 500 & 610 \\
\hline PT 1000 & 4008TAG2A & 1065 & 245 & 460 & 306 \\
\hline PT 1500 & 4012-46TAG2A & 1267 & 350 & 500 & 816 \\
\hline
\end{tabular}


of stages and generate the design parameters including the distilled water, size of the brine heater and the required sizing of MSF chambers. The proposed model will implement the brine mixing MSF approach rather than the one-through approach because of its higher productivity. The objective of brine recirculation is the decreasing the feed sea water flow rate which lowers the rate of chemical additive consumption and the pretreatment facilities size for the feed stream. shows the proposed system where the brine heater will be heated by the exhaust of the diesel generator. In order to maintain a low pressure at the last stages of the MSF, steam-jet ejector is used where the motive steam can be pumped from the distilled water with a special evaporator heater. Other evacuation equipment can be also used. Shell and tube heat exchanger is used for brine heater. The sea water enters the shell inlet at $T_{1}$ and leaves it at $T_{c_{0}}$ which is ready to enter the first flashing stage at a saturated state. The exhaust gas passes from the Diesel engine at $\mathrm{T}_{\text {gas, } \mathrm{i}}$ to the brine heater and will be admitted to the stack not less than not less than $180^{\circ} \mathrm{C}$. Although the model can deal with any number of MSF stages, eight chambers will be implemented due to the expected limitation of space in engine rooms in real applications.

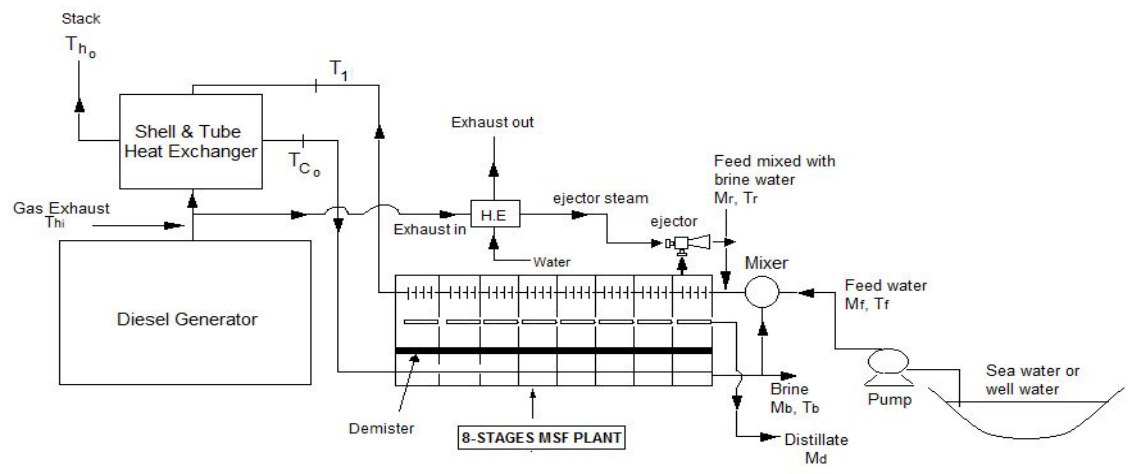

Figure 2: Schematic of diesel generator exhaust waste heat driven MSF-mixing desalination plant.

\section{Numerical analysis}

In the present study, the heat transfer area is equal in all flashing stages which has been approved as the basic practice in the desalination industry. It reduces design and construction costs and the stocking of different sizes of spare parts. Following [5], a number of simplifying assumptions are adopted in the present model which have a negligible effect on the accuracy of model predictions. These assumptions are:

- the distillate product is salt free;

- the subcooling of the condensate or the superheating of the heating steam has a negligible effect on the system energy balance; 
- the power requirements for pumps and auxiliaries are not considered in the system analysis; and

- $\quad$ the heat losses to the surroundings are negligible.

\subsection{Mathematical formulation of the mixing-bring MSF plant}

The equations used in the analyses include the continuity, energy balance, and heat transfer equations. The mass balance for the water leads to

$$
M_{f}=M_{b}+M_{d}
$$

and the salinity balance

$$
X_{f} \cdot M_{f}=X_{b} \cdot M_{b}
$$

where $M$ is the mass flow rate, $X$ the salt concentration, and the subscripts $b, d$, and $f$ denotes the brine, distillate, and feed streams, respectively.

The brine heater and condenser energy balances are given, respectively, by

$$
\begin{gathered}
M_{g a s} C_{P, g a s}\left(T_{g a s, o}-T_{g a s, i}\right)=M_{f} C_{P}\left(T_{o}-t_{1}\right) \\
M_{d} h_{v}=M_{f} C_{P}\left(T_{o}-T_{n}\right)
\end{gathered}
$$

where $C_{P}$ is the specific heat at constant pressure, $T$ the temperature of the flashing brine, $t$ the temperature of the seawater flowing in the condenser tubes, $h$ the latent heat of evaporation, the subscripts $o$ and 1 denote the brine stream entering and leaving the first stage, and the subscript $v$ denote the flashing vapor. $b h$ is

The heat transfer rate equation for the brine heater denoted by the subscript

$$
M_{g a s} \cdot C_{P, g a s}\left(T_{g a s, o}-T_{g a s, i}\right)=U_{b h} A_{b h}(L M T D)_{b h}
$$

where

$$
(L M T D)_{b h}=\left[\left(T_{g a s, i}-T_{o}\right)-\left(T_{g a s, o}-t_{1}\right)\right] / \ln \left[\frac{\left(T_{g a s, i}-T_{o}\right)}{\left(T_{g a s, o}-t_{1}\right)}\right]
$$

The heat transfer rate equation for the condenser is

$$
\begin{gathered}
M_{f} C_{f}\left(t_{1}-t_{2}\right)=U_{c} A_{c}(L M T D)_{c} \\
\text { where }(L M T D)_{c}=\left(t_{1}-t_{2}\right) / \ln \left[\frac{T_{v 1}-t_{2}}{T_{v 1}-t_{1}}\right]
\end{gathered}
$$


The heat balance equations are made for the recycle brine mixer. The equations include a mixer energy balance and salt balance, where

$$
\left(M_{r}-M_{f}\right) C_{P}\left(T_{n}-T_{c w}\right)=M_{r} C_{P}\left(T_{f}-T_{c w}\right)
$$

and the salinity balance reads

$$
M_{r} X_{r}=X_{f} \cdot M_{f}+X_{n}\left(M_{r}-M_{f}\right)
$$

The subscript $r$ refers to the recycled stream. The MSF model contains additional equations for the recycle salt balance, the cooling water energy balance and the temperature drop in the condensers in the rejection section. These equations are as follows:

$$
\begin{gathered}
X_{r}=\left[\left(X_{f}-X_{b}\right) M_{f}+M_{r} X_{b}\right] / M_{r} \\
M_{c w}=\left[M_{s} h_{s}-M_{f} C_{P}\left(T_{n}-T_{c w}\right)\right] /\left(C_{P}\left(T_{n}-T_{c w}\right)\right) \\
\Delta t_{j}=\left(T_{n}-T_{c w}\right) / j
\end{gathered}
$$

where $j$ is the $j^{t h}$ stage out of $n$ stages and it takes the value between 2 and $n$.

Width of the MSF stage

$$
\text { Width }_{\text {stage }}=M_{r} / V_{b}
$$

Length of the MSF stage

$$
\text { Length }_{\text {stage }}=\frac{M_{r} \cdot Y \cdot(1-Y)^{n}}{\rho_{\text {vapor }_{\text {stage }} \cdot V_{V_{n}} \cdot \text { Width }} \text { stage }_{\text {sta }}}
$$

The gate height of the MSF

$$
\mathrm{GH}_{\mathrm{i}}=\frac{\left(M_{r} \cdot 2 \cdot \rho_{\text {saltwater }} \cdot \Delta P_{\text {stage }_{i-1 ; i}}\right)^{-0.5}}{C_{d_{\text {wear }}} \cdot \text { width }_{\text {stage }}}
$$

The height of a demister that keeps the water vapor only goes to condenser

$$
\mathrm{H}_{\text {demister }}=0.1776 .\left(\exp ^{0.0054 . K_{h}}\right)
$$

where the height constant $K_{h}$ is obtained using the following relation:

$$
K_{h}=3.281 G_{v} /\left[\rho_{v}\left(\rho_{l} / \rho_{v}-1\right)^{0.5}\right]
$$

The height of the brine pool must be set higher than the gate height by 0.2 meters. 


\subsection{Mathematical formulation of the brine heater}

The brine heater is chosen to be a shell and tube heat exchanger; the most versatile type of industrial heat exchangers. It is responsible of rising the sea water temperature to a specified top brine temperature before entering into the MSF stages. The analysis presented here will provide the overall heat transfer coefficient of the brine heater $U_{b h}$ which is needed for Eq. (5) and the pressure drops in both the seawater and exhaust sides. The most important factor in the analysis is to limit the pressure drop in the exhaust side within the allowable back pressure indicated by the diesel engine.

Attention will be paid to the size of the brine heater length $(L)$ and diameter $\left(D_{s}\right)$ to be fit with the available space in the generator room and be proportional to the engine size in order to simplify the assembly process of the entire plant.

In the present study, Bell-Delaware method $[15,16]$ is applied in order to determine the heat transfer coefficient and pressure drop in the shell side.

The average heat transfer coefficient $h_{s}$ is calculated using the following relation

$$
h_{s}=h_{\text {ideal }} J_{C} J_{L} J_{B} J_{R} J_{S}
$$

where $h_{\text {ideal }}$ is the heat transfer coefficient for ideal flow over tube bank and is calculated from

$$
h_{\text {ideal }}=j c_{p, s}\left(m_{s}^{\circ} / A_{s}\right)\left(k_{s} / c_{p s} \mu_{s}\right)^{2 / 3}\left(\mu_{s} / \mu_{s w}\right)
$$

Here, $j$ is the Colburn $j$-factor for an ideal tube bank, $A_{s}$ is the cross-flow area at the centerline of the shell for one cross-flow between two baffles. The ideal values of Colburn $j$-factor may be calculated by using the curve fit correlations [15] which are expressed in the following forms

$$
j=a_{1}\left(\frac{1.33}{P_{T} / d_{o}}\right)^{a}\left(R e_{s}\right)^{a_{2}}, \quad a=\frac{a_{3}}{1+0.14\left(R e_{s}\right)^{a_{4}}}
$$

The correlation coefficients $a_{1}, a_{2}, a_{3}$ and $a_{4}$ are given by Serth [16] for wide range of Reynolds number in the shell. the correlation factors $J_{C}, J_{L}, J_{B}, J_{R}$, and $J_{S}$ appearing in Eq. (19) are the correction factors for the bypassing flow streams that deviate the real flow from the ideal flow over tube bank. They account for baffle window flow, baffle leakage effects, bundle bypass effects, laminar flow correction factor and correction for unequal baffle spacing, respectively. They are using complete set of equations taken from Serth [16].

The pressure drop across the shell side is calculated using the following relation:

$$
\begin{aligned}
\Delta P_{s}=\left[\left(n_{b}-1\right) \Delta\right. & \left.P_{\text {ideal }} R_{B}+n_{b} \Delta P_{w, \text { ideal }}\right] R_{L} \\
& +2 \Delta P_{\text {ideal }}\left(1+N_{c w} / N_{c}\right) R_{B} R_{S}
\end{aligned}
$$


where $n_{b}$ is the number of baffles, $\Delta P_{\text {ideal }}$ is the pressure drop for an ideal crossflow section, $\Delta P_{w}$ is the pressure drop for an ideal window section, $N_{c w}$ is the number of effective cross-flow rows in each window, $N_{c}$ is the number of tube rows crossed in one cross-flow section, $R_{L}$ is the correction factor for leakage streams, $R_{B}$ is the correction factor for bypass flow, and $R_{S}$ is the correction factor for unequal baffle spacing. Once tentative values of the shell diameter, tube diameter, baffles spacing, baffle cut, and number of tubes are estimated, the correction factors $R_{L}, R_{B}$, and $R_{s}$; and the numbers; $n_{b}, N_{c}$, and $N_{c w}$ can be computed. Details equations of all these variables are given by Serth [16].

The ideal pressure drop in the cross flow and in the window in case of turbulent flows, can be calculated as follows:

$$
\begin{gathered}
\Delta P_{\text {ideal }}=4 f_{s} \frac{G_{s}^{2}}{2 \rho_{s}}\left(\mu_{s w} / \mu_{s}\right)^{0.14} \\
\Delta P_{w, \text { ideal }}=\frac{\dot{m}_{s}^{2}\left(2+0.6 N_{c w}\right)}{2 \rho_{s} A_{s} A_{w}}
\end{gathered}
$$

where $G$ is the mass flux and $A_{w}$ is the area of the window in the baffle.

Similar to the Colburn $j$-factor, Serth provides a curve fitting correlation to obtain the friction factor in the shell side, $f_{s}$ in the form:

$$
f_{s}=b_{1}\left(\frac{1.33}{P_{T} / d_{o}}\right)^{b}\left(R e_{s}\right)^{b_{2}}, \quad b=\frac{b_{3}}{1+0.14\left(R e_{s}\right)^{b_{4}}}
$$

The $a$ 's and $b$ 's factors that appeared in Eqs. (21) and (25) are tabulated in Serth [16] based on Reynolds number in the shell and the tube layout. For simplicity, a square layout of the tube is selected in order to provide flexibility in cleaning the outer sides of the tubes. The tube side heat transfer correlations are given by the following Nusselt number correlation corresponding to turbulent flow which is mostly dominant inside the tubes as well as in the shell:

$$
h_{t}=0.023\left(k_{t} / d_{i}\right) \operatorname{Re}_{t}^{0.8} \operatorname{Pr}_{t}^{0.33}\left(\mu_{t} / \mu_{t w}\right)^{0.14}
$$

The tube side pressure drop is given by the following expression:

$$
\Delta P_{\text {tube }}=2 f_{t} \frac{G_{t}^{2} L N_{p}}{d_{i} \rho_{t}\left(\mu_{t} / \mu_{t w}\right)^{0.14}}
$$

where $N_{p}$ is the number of tube passes and $L$ is the tube length and subscript $t$ refers to the tube side.

The friction factor in the tube $f_{t}$ is calculated from the following relation:

$$
f_{t}=0.046 R e_{t}^{-0.2}
$$


Once the heat transfer coefficients in the shell $h_{s}$ and in the tube $h_{t}$ are calculated, the overall heat transfer coefficient of the brine heater $U_{b h}$ can be obtained. Relations for the heat transfer coefficients and specific heat at constant pressure of seawater are typical to those used by El-Dessoukey and Ettouney [5]. The above equations are solved using Engineering Equation Solver EES software.

\section{Results and discussions}

Verification of the mathematical formulation is done by comparing the steam driven MSF done by El-Dessoukey and Ettouney [5]. Comparison between summer and winter operation is shown in . Excellent agreement with the numerical values can be seen in the figure. Comparisons with El-Dessoukey and Ettouney's data for different number of stages, different top brine temperatures and in different seasons are done revealing reasonable matching. The agreement shown indicates that the present mathematical model is reliable for waste heat recovery calculations.

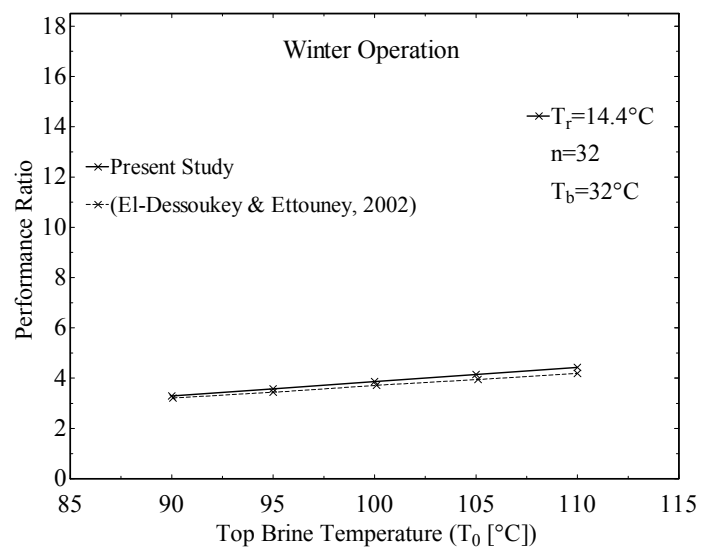

Figure 3: Comparison with data of El-Dessoukey and Ettouney (2002).

Various operating parameters have been evaluated using the present model. Sample of the assessment is shown in , in which the salinity of the feed water changes between 10,000 to $40,000 \mathrm{ppm}$. The amount of distillate water is larger in summer than that in winter and it inversely proportional to the salinity of the water. The full list of database of diesel generators is used to determine the amount of distillate water that can be produced at each engine capacity. Two salinity values are used; 37,000 ppm corresponding to the Mediterranean sea and 10,000 ppm corresponding to the brackish water level in most areas of Lebanon. The number of MSF stages in the following analyses is limited to 8 stages due to the expected limitation of the space in engine rooms. The produced distillate water flow rate is plotted for both summer and winter conditions in . The cooling water temperature changes from $10^{\circ} \mathrm{C}$ in winter to $25^{\circ} \mathrm{C}$ in summer. The design of the heat exchanger 
in this part of the study has been performed without limitation on sizing. The only restriction is the back pressure on the engine. Based on the above conditions, two correlations are derived for sea and brackish water during summer and winter operation. Each correlation can give roughly the expected amount of distillate water/kVA of the engine capacity. The correlations reveal a second order dependency on engine kVA rather than the linear correlation derived by Mustafa et al. [14] and the rate of the distillate water is larger than that derived by them $\left(M_{d}=0.0095+0.0044 \mathrm{kVA}\right.$ in $\left.\mathrm{kg} / \mathrm{s}\right)$. This may be attributed to the improvements on technologies of diesel engine in recent years.
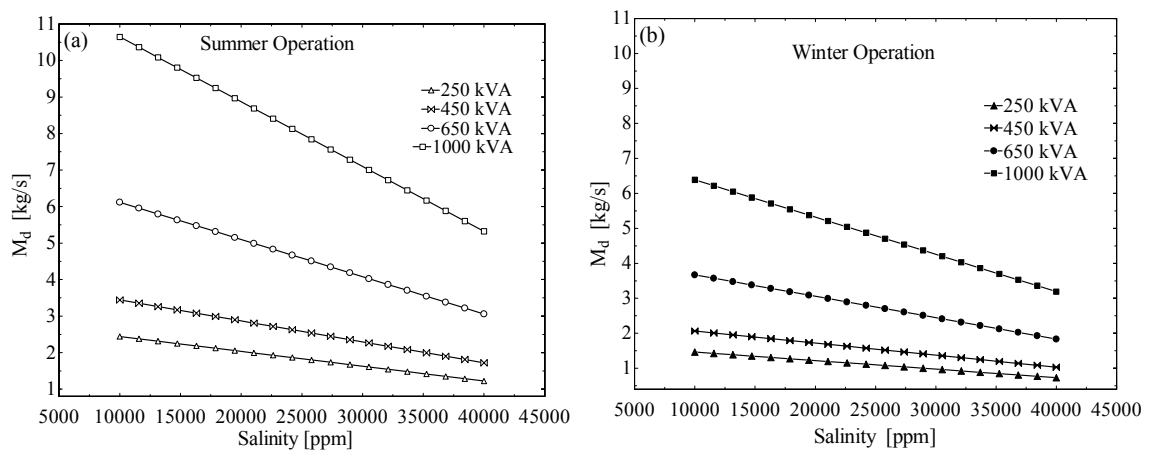

Figure 4: Distillate flow rate production versus water salinity.
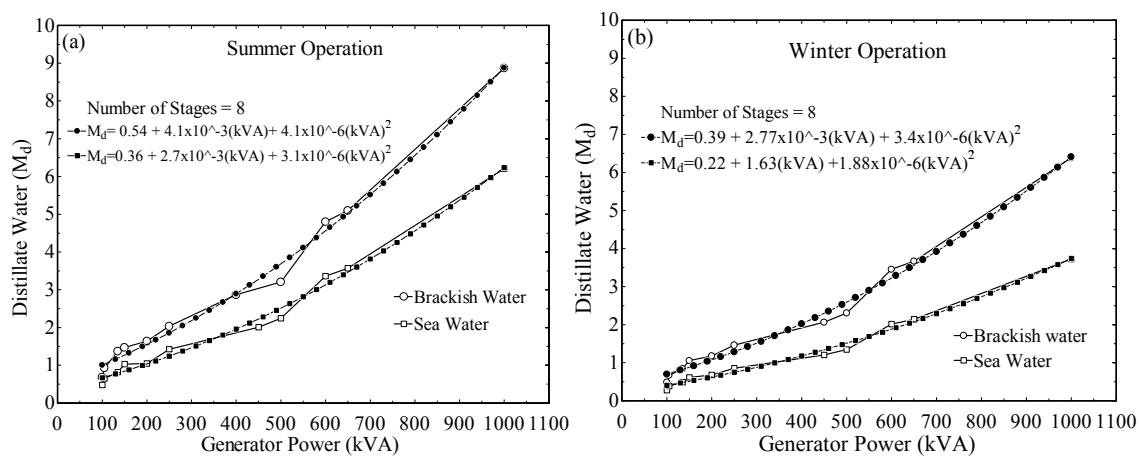

Figure 5: Distillate flow rate production versus generator capacities.

Two study cases have been carried out using the mathematical model. In Case (1), three sets of $450 \mathrm{kVA}$ Diesel generators is Beirut Arab University DEBBIEH Campus are used to desalinate brackish water of 10,000 ppm. In Case (2) two set of $1000 \mathrm{kVA}$ Diesel generators in a hotel near the seaside are used with seawater of salinity $37,000 \mathrm{ppm}$. The number of stages is kept at $8 \mathrm{MSF}$ stages. shows the effect of the rejected brine temperature $T_{b}$ on both the distillate water and the rejected brine flow rates in summer and winter operation. In general, the flow rates decrease with increasing $T_{b}$. The amount of distillate water in case of the brackish 
is smaller than the rejected brine flow rate due to the limitation on the rejected brine salinity in mountain side areas to be less than $35,000 \mathrm{ppm}$. In Case (2), the rejected brine may reach to $70,000 \mathrm{ppm}$, which allows for higher flow rate of the distillate water and lower flow rate of the rejected brine. Details about the data of the flash chamber listed in .
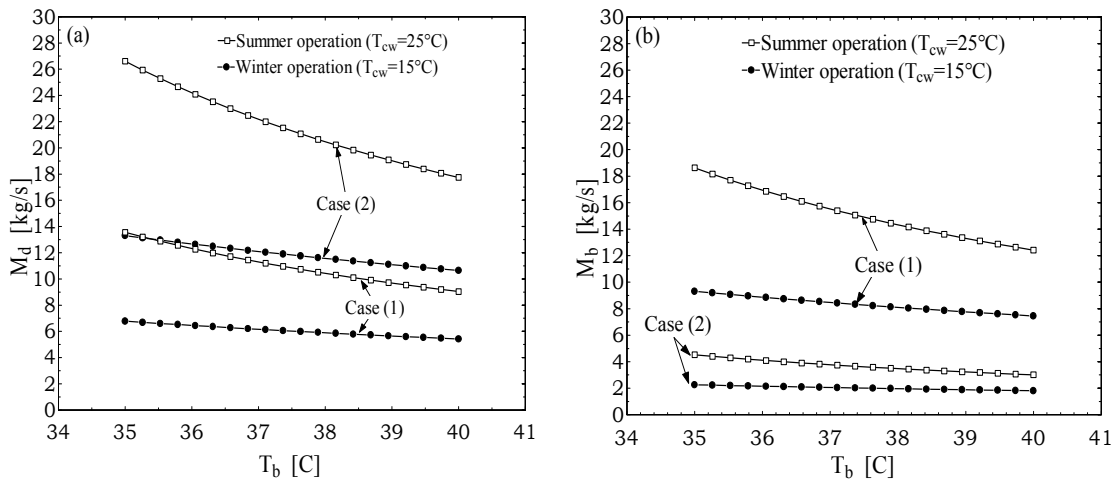

Figure 6: Effect of rejected brine temperature on: (a) Distillate water flow rate and; (b) rejected brine flow rate.

Table 2: Data of each stage of the MSF desalination plant.

\begin{tabular}{|c|c|c|c|c|c|c|c|}
\hline $\mathrm{n}$ & Case & $\begin{array}{c}m_{d i} \\
(\mathrm{~kg} / \mathrm{s})\end{array}$ & $\begin{array}{c}m_{b i} \\
(\mathrm{~kg} / \mathrm{s})\end{array}$ & $X_{i}(\mathrm{ppm})$ & $T_{b i}\left({ }^{\circ} \mathrm{C}\right)$ & $G H_{i}(\mathrm{~m})$ & $\begin{array}{c}H_{\text {Demister.i }} \\
(\mathrm{m})\end{array}$ \\
\hline \multirow{2}{*}{1} & $(1)$ & 0.8066 & 71.61 & 32000 & 88.13 & 0.061 & 0.178 \\
\cline { 2 - 8 } & $(2)$ & 1.164 & 103.4 & 64481 & 83.75 & 0.01598 & 0.1779 \\
\hline \multirow{2}{*}{2} & $(1)$ & 0.7977 & 70.81 & 32603 & 85.83 & 0.01783 & 0.1779 \\
\cline { 2 - 8 } & $(2)$ & 1.151 & 102.2 & 65207 & 77.5 & 0.01757 & 0.1779 \\
\hline \multirow{2}{*}{3} & $(1)$ & 0.7888 & 70.02 & 32971 & 71.25 & 0.01969 & 0.1779 \\
\cline { 2 - 8 } & $(2)$ & 1.138 & 101.1 & 65941 & 71.25 & 0.0194 & 0.1779 \\
\hline \multirow{2}{*}{4} & $(1)$ & 0.78 & 69.24 & 33342 & 65 & 0.02183 & 0.1778 \\
\cline { 2 - 8 } & $(2)$ & 1.126 & 99.94 & 66684 & 65 & 0.02151 & 0.1778 \\
\hline \multirow{2}{*}{5} & $(1)$ & 0.7713 & 68.47 & 33718 & 58.75 & 0.02431 & 0.1778 \\
\cline { 2 - 8 } & $(2)$ & 1.113 & 98.83 & 67435 & 58.75 & 0.02396 & 0.1778 \\
\hline \multirow{2}{*}{6} & $(1)$ & 0.7627 & 67.71 & 34097 & 52.5 & 0.02719 & 0.1778 \\
\cline { 2 - 8 } & $(2)$ & 1.101 & 97.73 & 68195 & 52.5 & 0.0268 & 0.1778 \\
\hline \multirow{2}{*}{7} & $(1)$ & 0.7542 & 66.96 & 34482 & 46.25 & 0.03057 & 0.1778 \\
\cline { 2 - 8 } & $(2)$ & 1.089 & 96.64 & 68963 & 46.25 & 0.03013 & 0.1777 \\
\hline \multirow{2}{*}{8} & $(1)$ & 0.7458 & 66.21 & 34870 & 40 & 0.03454 & 0.1777 \\
\cline { 2 - 7 } & $(2)$ & 1.076 & 95.56 & 69740 & 40 & 0.03405 & 0.1777 \\
\hline
\end{tabular}




\section{Conclusion}

The EES analysis program for exhaust heat recovery for MSF desalination unit integrated with wide range of diesel engines can deal with any sets and power (kVA) of Diesel engines with any condition of water (well, sea, brackish...) and for the all semesters. This program gives the details of the shell and tube heat exchanger responsible for the recovering of heat and its dimensions parameters.

The program can work with two types of MSF desalination, the one through and the brine mixing with a stages number up to 32 stages according to the available area, cost and demand.

The present study selects a MSF desalination unit with eight stages for brine mixing type which is more efficient and gives more distillate water according to presented heat recovered from a specified set of Diesel engines. Inputs and outputs data are available after selection of the Diesel engine sets and then the design parameters of the heat exchanger and the MSF plant are gutted from the present study and program.

It can be shown from the results of the presented study that the summer production of distillate water is high in comparison with winter semester because of variation of the feed water temperature which is high in summer and affects the distillate water productivity.

Studying of the discontinuity of the operation of Diesel generators in result of the discontinuity of the EDL electricity power supply in Lebanon and studying of the continuity of producing distillate water around the clock in dependence from the effect of the EDL electricity power.

Designing a waste heat recovery system for a diesel generator containing three waste heat systems, oil, water jacket and exhaust gas and collecting them in one system with a MSF desalination unit.

\section{References}

[1] Rosegrant, M. W., Cai, X., and Cline, S. A., (2013). "World water and food to 2025; Dealing with scarcity", International Food Policy Research Institute (IFPRI).

[2] Fateh, H. S., (2002) Desalination Technology. Al-Dar Publisher, Alexandri, Egypt: الدار الجامعية الإسكندرية.

[3] Allan, J. A., (2002) "The middle east water question," I. B. Tauris Publishers, London and New York.

[4] Tropp, H., and Jagerskog, A., (2006) "Water Scarcity Challenges in the Middle East and North Africa (MENA)," Human development office.

[5] El-Dessoukey, H., and H. Ettouney, H. (2002). "Fundamentals of Salt water Desalination," ELSEVIER.

[6] Lin, C.-S (2008). "Capture of Heat Energy from Diesel Engine Exhaust," United States Department of Energy, National Energy Technology Laboratory. Available online at: http://dx.doi.org/10.2172/963351.

[7] Bjerde, A., Convindassamy, A., Hamaide, M., Takahashi, M., and Araujo, A. (2008) "Electricity Sector Public Expenditure Review," World Bank Archive, Middle East, World Bank. 
[8] Darwish, M. Fouad, Y. and Al-Najem, N. (1997) "Energy consumption and costs with multi-stage flashing (MSF) desalting system," Desalination, Vol. 109, pp. 285-302.

[9] Geara, D. (2010). "State of Art about Water Uses and Waste Water Management in Lebanon," Lebanese Science Journal, Vol. 11, pp. 139-152.

[10] Williams, J. and Hodgson, A. (1968) "Multistage flash desalination unit utilizing diesel generator waste heat," Ph.D. Dissertation, Naval Civil Engineering Laboratory, California, USA.

[11] Toelkes, W. E. (1987). "The Ebeye Desalination Project - Total Utilization of Diesel Waste Heat," Desalination, Vol. 66, pp. 59-68.

[12] Rautenbach, R. and Arzt, B., (1985). "Gas Turbine Waste Heat Utilization for Distillation," Desalination, Vol. 52, pp. 105-122.

[13] Aly, S. E. (1987). "Gas Turbine Waste Heat Recovery distillation System," Heat Recovery Systems \& CHP, Vol. 7, No. 4, pp. 375-382.

[14] Moustafa, S., Al-Shami, H., Jarrar, D. and El-Mansy, H., (1982). "Integrated diesel powered greenhouse-MSF desalination system for desert application," Energy in Agriculture, vol. 1, pp. 303-310.

[15] Kakac, S., Liu, H., (2002). Heat exchangers selection, rating, and thermal design. Florida: CRC Press.

[16] Serth, R., (2007). Process heat transfer, Principles and applications. Elsevier Science \& Technology Books.

[17] Klein, S.A. and Nellis, G.F. (2012), “Mastering EES," f-Chart software. 